WellBeing International

WBI Studies Repository

$5-2016$

\title{
Are Domestic Pigs (Sus scrofa domestica) Able to Use Complex Human-Given Cues to Find a Hidden Reward?
}

\author{
Christian Nawroth \\ Martin Luther Universitat Halle-Wittenberg \\ Mirjam Ebersbach \\ University of Kassel \\ Eberhard von Borell \\ Martin Luther Universitat Halle-Wittenberg
}

Follow this and additional works at: https://www.wellbeingintlstudiesrepository.org/soccog

Part of the Animal Studies Commons, Comparative Psychology Commons, and the Other Animal

Sciences Commons

\section{Recommended Citation}

Nawroth, C., Ebersbach, M., \& Von Borell, E. (2016). Are domestic pigs (Sus scrofa domestica) able to use complex human-given cues to find a hidden reward?. Animal Welfare, 25(2), 185-190.

This material is brought to you for free and open access by WellBeing International. It has been accepted for inclusion by an authorized administrator of the WBI Studies Repository. For more information, please contact wbisr-info@wellbeingintl.org.

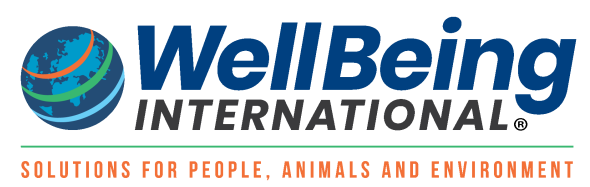




\section{Are domestic pigs (Sus scrofa domestica) able to use complex}

\section{human-given cues to find a hidden reward?}

\section{Christian Nawroth $^{*}{ }^{1}$, Mirjam Ebersbach ${ }^{2}$ and Eberhard von Borell ${ }^{1}$}

${ }^{1}$ Department of Animal Husbandry \& Ecology, Institute of Agricultural and Nutritional Sciences, Martin-Luther-University, Halle, GER

${ }^{2}$ Department of Developmental Psychology, Institute of Psychology, University of Kassel, Kassel, GER

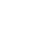

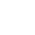

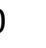

11

2

3

\section{* Corresponding author}

Present address:

9 Biological and Experimental Psychology

20 School of Biological and Chemical Sciences

1 Queen Mary University of London

2 Mile End Road

3 London E1 4NS, UK

4 Email address: nawroth.christian@gmail.com 


\section{Abstract}

Understanding human-animal interactions in livestock production systems is crucial for improving animal welfare. It is therefore of general interest to investigate how livestock animals obtain information from humans. By using an object-choice paradigm, we investigated whether domestic pigs $(n=4)$ are able to use a variety of human-given cues, such as different pointing gestures, to find a hidden food reward. In Experiment 1, an experimenter pointed towards a baited location in front of the pig while the extent of the protrusion of his hand from the upper body was varied. Pigs had problems using pointing gestures that did not protrude from the upper body of the experimenter, but were able to successfully use a long cross pointing administered with the contralateral hand of an experimenter to find a hidden reward. In Experiment 2, an experimenter indicated a baited location that was behind the pig using either a pointing gesture, his body or his head orientation. All four individuals used the pointing gesture and one pig was able to use the head orientation to find the hidden reward. The results provide additional evidence of pigs' ability to use novel human-given cues as well as its constraints, and will contribute to a better understanding of pigs' perception of their stockpersons and handlers.

Keywords: animal welfare; domestic pigs; human-animal interaction; human-given cues; object choice paradigm; pointing gesture 


\section{Introduction}

Understanding human-animal interactions in livestock production systems is crucial for progress in improving animal welfare (Hemsworth 2003), and experiments investigating those interactions can contribute to reducing stress during handling and transport (Jago et al 1999; Probst et al 2012) or during routine handling practices (Muns, Rault, \& Hemsworth, 2015). Previous studies have shown that early direct interactions between calves or heifers and their handlers (e.g., stroking) lead to positive physiological outcomes, including less stress and fear of humans (Boissy \& Bouissou 1988; Stewart et al 2013). It is particularly important to know what type of stockperson behaviour may serve as stressor for the individual. Further it is also relevant to investigate the information an animal obtains from the stockperson or handler in general as a stockperson's gesture or action might be comprehended by the individual in terms of referring to a positive or negative event. To improve human-animal interactions in production systems, it is therefore important to know what particular information farm animals extract from human behaviour. For instance, studies have shown that pigs are sensitive to the posture of humans (Hemsworth et al 1986; Miura et al 1996; Nawroth et al 2013), although the particular kind of information that livestock animals use to guide their response behaviour is largely unknown. In general, a better understanding of the perceptive and cognitive capacities of livestock animals is necessary to better understand their normal behavioural expressions, needs, and motivations and to avoid exposing them to mental distress, e.g. through poor handling practices.

One commonly used test paradigm to investigate human-animal communicative capacities is a so-called object choice task. In this test, an individual has to choose between two or more locations, one of which covers a hidden food reward which is indicated by a human experimenter through a communicative cue (e.g. pointing gesture or head orientation; 
Udell et al 2008), other domesticated species, such as goats, Capra hircus (Kaminski et al 2005), horses, Equus caballus (Maros et al 2008; Proops et al 2010) and pigs, Sus scrofa (Nawroth et al 2014), appear to be able to use human pointing gestures to find a hidden food reward.

Procedural changes in the object choice task can help to shed light on how individuals use information provided by a human, e.g. through a pointing gesture. For example, the type of the pointing gesture can be modified in several ways. This is based on the presumption that the ability to generalize from the basic ipsilateral pointing gesture to novel forms, such as pointing gestures with the contralateral arm, might reveal representational understanding, such as the comprehension of the referential nature of these pointing gestures. Results from dogs suggest that they are sensitive to the relation between hand/arm and upper body of the experimenter; that is, they infer the directionality of the gesture by observing the direction in which part of the arm/hand protrudes from the upper body (Soproni et al 2002; Lakatos et al 2009). Another alternative is a pointing gesture towards potentially rewarded locations that are actually positioned behind the tested individual. A simple approach toward the movement of the hand (i.e., the use of stimulus enhancement) would therefore not yield a reward. Instead, an individual would have to move away from the experimenter, which is cognitively more demanding (Riedel et al 2008).

Domestic pigs at the age of seven weeks have been shown to use various pointing gestures as well as the body and head orientation of an experimenter to find a hidden food reward (Nawroth et al 2014). However, it was not clear if the performance in the tasks using the pointing gesture could be explained due to rapid learning or due to representational understanding. In the present study, we therefore wanted to investigate if and how pigs are able to use new and unfamiliar human-given cues by applying an object choice task that involved several modifications compared to Nawroth et al (2014) with regard to the gesture given by the human and the positions of the hiding locations. In Experiment 1, we varied the 
protrusion of the experimenter's hand from the upper body during pointing gestures on baited locations. It has been shown that dogs, but not children, had problems using pointing gestures that did not protrude the upper body of the human, indicating that they only use protruding body parts as a cue (Soproni et al 2002; Lakatos et al 2009). In Experiment 2, the baited location was behind the tested pig. If pigs are able to generalize the gestural cue, they should be able to find the baited location in both experiments, at least when the gestures protruded the body of the experimenter.

\section{General methods}

Four female pigs [[German Edelschwein $\times$ German Landrace $] \times$ Pietrain] at the age of ten weeks participated. They were kept in a group with five conspecifics. All pigs had previously participated in a study by Nawroth et al (2014). In this previous study, four out of the nine subjects never proceeded to the training phase or they lost motivation during test trials. One pig developed a strong side bias during the tests. Therefore, we tested the four remaining pigs that (1) did not develop a side bias and (2) did not lose motivation to participate in any of the previous tasks. Pigs were housed in a barn at the Institute of Agricultural and Nutritional Sciences in Merbitz, Germany. Pigs were group-housed in pens $(250$ x $400 \mathrm{~cm})$ on solid floor with straw bedding, temperature was maintained at about $23^{\circ} \mathrm{C}$ and artificial light was provided from $0700 \mathrm{~h}$ to $1700 \mathrm{~h}$. The experiments were carried out at facilities of the Institute of Agricultural and Nutritional Sciences of the University of Halle-Wittenberg under license of the regional veterinary control board. Housing facilities met the German welfare requirements for farm animals. Pigs had water and food access via a hopper ad libitum all the time. All individuals were already habituated to a test area and the general setup (for habituation, training procedure and previous experience with human-given cues see Nawroth et al 2014 and supplementary material ESM1). 


\section{Experiment 1}

127 In Experiment 1, we administered four pointing gestures with different degrees of how the

128 hand of the experimenter protruded from his torso. These variations in the pointing gesture

129 were already applied to dogs but not to other domesticated species so far (Soproni et al 2002;

130 Lakatos et al 2009). The proximal pointing gesture has previously been used by Nawroth et al.

131 (2014).

132

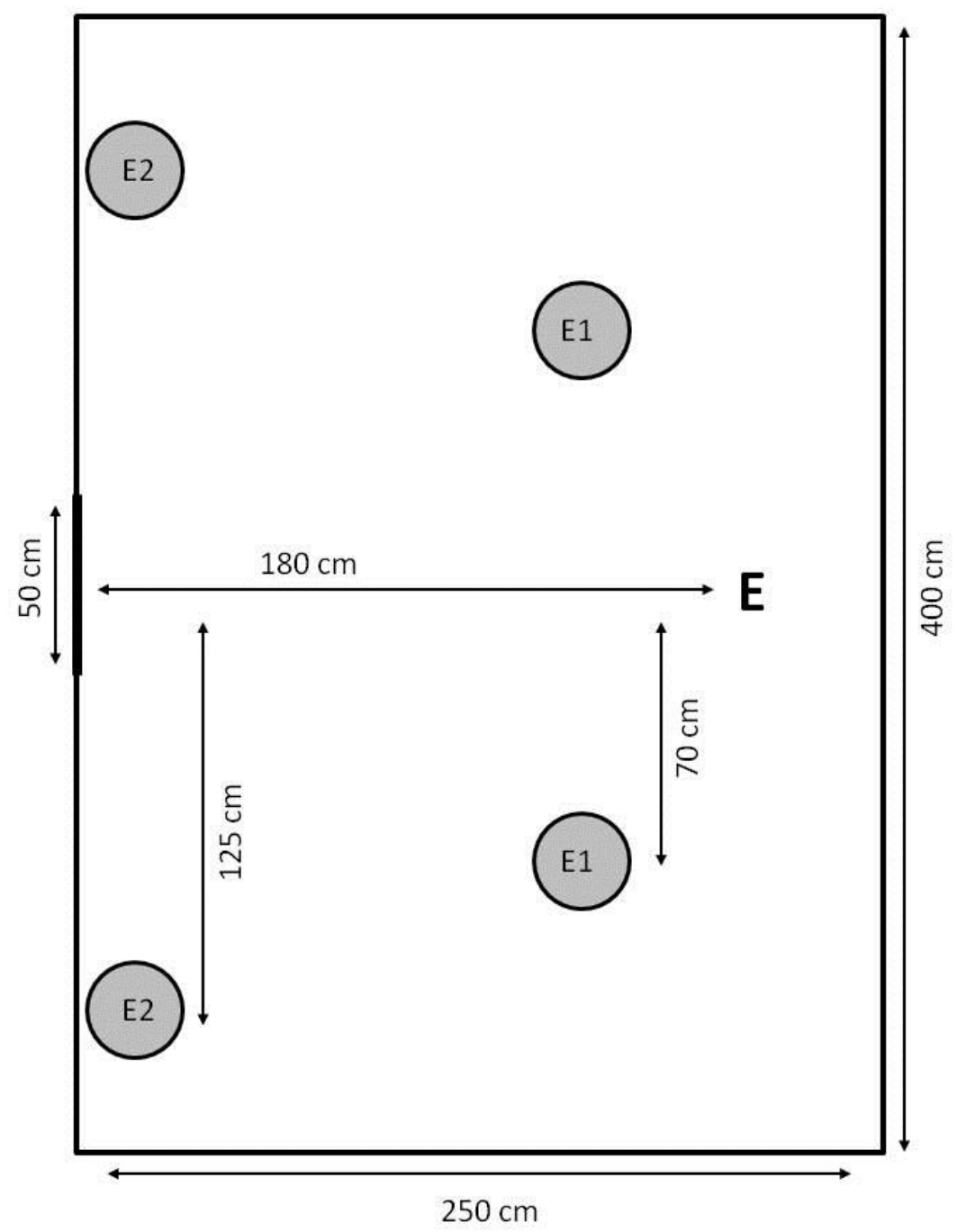


Fig. 1 Measurements of the test area. E: Position of the experimenter in both experiments; E1: Position of bowls in Experiment 1; E2: Position of bowls in Experiment 2

\section{Procedure}

Two bowls (20 cm diameter) were placed $150 \mathrm{~cm}$ away from the entrance and $140 \mathrm{~cm}$ apart from each other with the experimenter kneeling between the two bowls about $30 \mathrm{~cm}$ behind the midline (see Fig. 1). Before each test session, individuals received two training trials. Pigs were allowed to enter the area with both bowls present and either the left or the right bowl was baited with a grape. This was done to ensure that they recognized that only one food bowl was baited. Once they had received the reward, they were sent back from the test area into an adjacent resting area. In test trials, pigs were allowed to enter the area from the adjacent resting area via an opaque plastic corridor of $1.5 \mathrm{~m}$ length. Pigs were allowed to choose one bowl in each trial. When subjects approached the correct bowl, they were allowed to feed from it. When subjects approached the incorrect bowl, they received no reward. After each choice, either correct or incorrect, pigs were slightly forced to return to the resting area. We administered the following four conditions with each individual pig (see Fig. 2):

$$
\text { with his ipsilateral arm towards the baited bowl. The distance between the tip of the }
$$
experimenter's index finger and the baited bowl was about $30 \mathrm{~cm}$. The experimenter remained in this position until the subject made a choice.

Long cross pointing: As soon as the pig entered the corridor, the experimenter pointed with his contralateral arm outstretched straight towards the baited bowl. The distance between the tip of the experimenter's index finger and the baited bowl was about $45 \mathrm{~cm}$. The experimenter remained in this position until the subject made a choice. 
with his contralateral arm towards the baited bowl. No parts of the arm hereby protruded the experimenters' upper body. The distance between the tip of the experimenter's index finger and the baited bowl was about $80 \mathrm{~cm}$. The experimenter remained in this position until the subject made a choice.

Elbow cross pointing: As soon as the pig entered the corridor, the experimenter pointed with his contralateral arm towards the baited bowl. The experimenters elbow hereby protruded his upper body. The distance between the tip of the experimenter's index finger and the baited bowl was about $80 \mathrm{~cm}$. The experimenter remained in this position until the subject made a choice.

In all trials, the experimenter was looking straight forward and engaged in a neutral face expression. Each pig received six sessions on six consecutive days, with 20 trials each, and every session consisted of five trials for each of the four conditions, resulting in 30 trials for each condition in total. Side and cue type were counterbalanced across a session with the exception that no side or cue type was provided more than three times in a row. When pigs were distracted or not motivated anymore (e.g. did not enter the test area for more than three minutes), a session was terminated and completed the following day. After the end of all test sessions, twelve control trials were conducted to rule out other factors, e.g. odour cues, influencing pigs' decision making ('control near'). We presented the control trials en bloc as previous pilot tests have shown that subjects are likely to develop side biases when no cue at all was provided during test sessions. In these control trials, the experimenter remained motionless without indicating the baited bowl. 


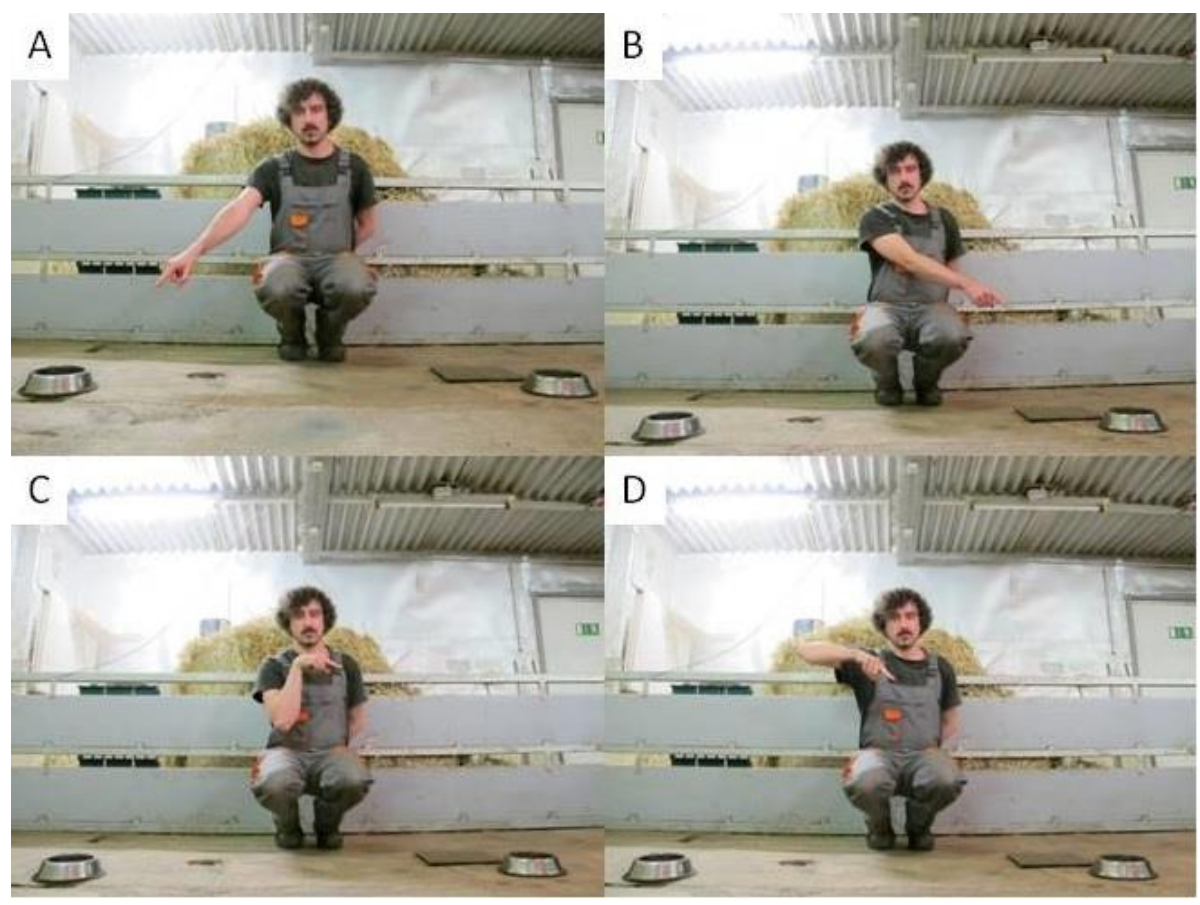

Fig. 2 Images of the different human-given cues in Experiment 1: a proximal pointing, b long cross pointing, $\mathbf{c}$ short cross pointing, $\mathbf{d}$ elbow cross pointing

\section{Data scoring and analysis}

We conducted binomial tests to analyse whether individual pigs chose correctly above the level of chance (i.e., 21 times or more out of 30 trials; two-tailed $P=0.043$ ). We also analysed individual learning effects by comparing the first against the last 15 trials, using an exact Chi-square test. All choices could be classified unambiguously as correct or incorrect, so that we did not calculate inter-observer reliability.

\section{Results}

All pigs used the proximal and the long cross pointing significantly above chance to find the hidden reward (see Table 1). None of the individuals performed above chance with the short cross and elbow cross pointing, i.e., where the hand of the experimenter did not protrude his 
torso towards the correct direction (all $P \mathrm{~s}>0.05$ ). One pig ('U') performed significantly

202 below chance level during the administration of the elbow cross pointing $(P<0.01)$. None of 203 the pigs' performances changed between the first and last 15 trials (all $P$ s $>0.1$ ).

Table 1 Individual performance of pigs in test and control condition. Bold numbers indicate performance significantly above (21 or more correct trials in test condition, 10 or more trials 207 in control condition; two-tailed $P<0.05$; binomial test) or below the level of chance ( 9 or less correct trials in test conditions, 2 or less correct trials in control condition; two-tailed $P<$

0.05; binomial test).

\begin{tabular}{cccccc|cccc} 
Subject & Proximal & Long cross & Short cross & Elbow cross & Control near & Point & Body & Head & Control far \\
& 30 trials & 30 trials & 30 trials & 30 trials & 12 trials & 30 trials & 30 trials & 30 trials & 12 trials \\
\cline { 2 - 9 } P & $\mathbf{3 0}$ & $\mathbf{2 7}$ & 16 & 11 & 6 & $\mathbf{2 8}$ & 17 & $\mathbf{2 1}$ & 7 \\
R & $\mathbf{3 0}$ & $\mathbf{2 3}$ & 17 & 16 & 8 & $\mathbf{2 5}$ & 12 & 13 & 5 \\
T & $\mathbf{3 0}$ & $\mathbf{3 0}$ & 14 & 11 & 6 & $\mathbf{2 8}$ & 17 & 17 & 5 \\
$\mathrm{U}$ & $\mathbf{3 0}$ & $\mathbf{2 6}$ & 16 & $\mathbf{7}$ & 6 & $\mathbf{2 2}$ & 11 & 14 & 6 \\
\hline
\end{tabular}

\section{Experiment 2}

In a second experiment, we administered different human-given cues towards one of two locations that were behind the individual (see Fig. 1).

\section{Procedure}

218 Two bowls were placed directly at the line of the entrance and therefore behind the pig when

219 it had fully entered the area (see video ESM2). The bowls were positioned $250 \mathrm{~cm}$ apart from each other with the experimenter about $180 \mathrm{~cm}$ behind the midline kneeling between the two

221 bowls (see Fig. 1). Before each test session, individuals received two training trials. The 
general procedure for training and test trials were similar to Experiment 1. During the presentation of the following three human-given cues, the experimenter remained in a squatting position:

Pointing: As soon as the pig entered the corridor, the experimenter pointed with his ipsilateral arm towards the baited bowl. The distance between the tip of the experimenter's index finger and the baited bowl was about $150 \mathrm{~cm}$. The experimenter remained in this position until the subject made a choice.

Body orientation: As soon as the pig entered the corridor, the experimenter turned his body and head towards the baited bowl. The distance between the experimenter and the baited bowl was about $210 \mathrm{~cm}$. The experimenter remained in this position until the subject made a choice.

Head orientation: As soon as the pig entered the corridor, the experimenter turned only his head towards the baited bowl. The distance between the experimenter and the baited bowl was about $210 \mathrm{~cm}$. The experimenter remained in this position until the subject made a choice.

In all trials, the experimenter was looking straight forward and engaged in a neutral face expression. Each pig received six sessions with 15 trials and each session consisted of five trials for each of the three conditions, resulting in 30 trials for each condition in total. Side and cue type were counterbalanced across a session with the exception that no side or cue type was provided more than three times in a row. When pigs were distracted or not motivated anymore (e.g. did not enter the test area for more than 3 minutes), a session was terminated and completed the following day. After all test sessions, twelve control trials were conducted to rule out other factors influencing pigs' decision making ('control far'). In these control trials, the experimenter remained motionless without indicating the baited bowl. 


\section{Data scoring and analysis}

Data scoring and analysis was the same as in Experiment 1.

\section{Results}

All individuals performed significantly above chance in the 'Pointing' condition (see Table 1 and video ESM2). None of the pigs performed above chance in the 'Body orientation' condition. In the 'Head orientation' condition, pig ' $\mathrm{P}$ ' chose the correct bowl 21 out of 30 trials $(P=0.043)$. All other individuals remained at chance level. Pig ' $\mathrm{R}$ ' slightly improved its performance in the 'Body orientation' condition (first half: 3/15 trials correct, second half: 9/15 trials correct; exact $P=0.06$ ). The performance of the other pigs did not change between the first and the last 15 trials (all $P$ s $>0.1$ ).

\section{Discussion}

Two experiments were conducted to investigate pigs' use of human-given cues to find a hidden food reward. Pigs in Experiment 1 had problems using pointing gestures that did not protrude the upper body of the experimenter to find the hidden reward. However, they easily generalised to use long cross pointings, a gesture with which they were not familiar before. In Experiment 2, pigs had to move away from the experimenter to gain a reward. Thus, a simple hand-food association was not sufficient to perform above chance level. Here, all four

271 individuals used a sustained human pointing gesture and, in addition, one pig was able to use

272 the human head direction as a cue. The results from the two experiments confirm previous positive findings on the good performance of pigs to use human-given cues (Nawroth et al 
2014) and show that pigs encounter similar constraints in using these cues as dogs do, namely the necessity of the protrusion of some body parts towards the rewarded location, (Soproni et al 2002; Lakatos et al 2009). However, more research is needed to assess if pigs, which are not bred for companionship, share some of the same capacities to communicate with humans as dogs do.

Despite the presentation of novel pointing gestures and baiting locations, performance of all individuals was at a high level from the beginning of the experiments while only one pig showed signs of learning. Pig ' $R$ ' improved its performance in Experiment 2 when the body orientation of the experimenter was directed towards a baited location. The performance increased from $3 / 15$ correct trials in the first half to $9 / 15$ correct trials in the second half, indicating a potential initial avoidance behaviour towards the experimenter's body orientation, which was, however, not observed in the other pigs.

To ensure that pigs' performance in Experiment 2 was not simply due to following the shortest path between the experimenter's hand and the nearest bowl, further tests are necessary. In addition, pigs had extensive experience in using pointing gestures prior to the experiments (a total of 220 test trials for each subject), but all pigs already showed a performance significantly above chance level when tested the first time with a sustained proximal pointing cue (see Nawroth et al 2014). However, it would be of interest if naïve pigs would be able to interpret these cues as well. Future studies should also implement additional test variations that may provide insights into the mechanism at work, i.e., if pigs actually comprehend the referential nature of the pointing gesture.

A direct implementation of our results into handling practices is difficult as training and habituation requires a lot of time. However, previous research has shown that even subtle changes in human posture (Hemsworth et al 1986; Nawroth et al 2013) and short exposure towards human contact (Muns et al 2015; Tallet et al 2014) can alter pigs behaviour. In addition, positive interactions have been recently shown to alter their emotional state (Brajon 
et al 2015). Thus understanding what pigs comprehend in particular about human behaviour is

301 crucial for progress in the development of new handling practices. As an indirect 302 implementation, our results can contribute to extend knowledge about basic cognitive

303

\section{Acknowledgment}

312

313 We would like to thank Volker Kutzner for building the test apparatus. We are grateful for the comments of the editor and two anonymous reviewers which helped to improve the capacities of pigs and inspire further research on the underlying mechanisms, which will help to gain a better understanding of human-animal interaction and to improve handling practices. In conclusion, the results provide further evidence about the ability of pigs to use novel human-given cues as well as its constraints, whereas the particular mechanism at work has to be further evaluated. This line of research will contribute to a better understanding of pigs' perception of their stockpersons and handlers and will thus improve welfare in the long term (Hemsworth 2003; Waiblinger et al 2006). manuscript significantly. 
Boissy, A., \& Bouissou, M.-F. (1988). Effects of early handling on heifers' subsequent reactivity to humans and to unfamiliar situations. Applied Animal Behaviour Science, 20(3-4), 259-273. http://doi.org/10.1016/0168-1591(88)90051-2

Brajon, S., Laforest, J.-P., Schmitt, O., \& Devillers, N. (2015). The Way Humans Behave Modulates the Emotional State of Piglets. Plos One, 10(8), e0133408. http://doi.org/10.1371/journal.pone.0133408

Hare, B., Brown, M., Williamson, C., \& Tomasello, M. (2002). The domestication of social cognition in dogs. Science, 298(5598), 1634-1636.

Hemsworth, P. . (2003). Human-animal interactions in livestock production. Applied Animal Behaviour Science, 81(3), 185-198. http://doi.org/10.1016/S0168-1591(02)00280-0

Hemsworth, P. H., Gonyou, H. W., \& Dziuk, P. J. (1986). Human communication with pigs: the behavioural response of pigs to specific human signals. Applied Animal Behaviour Science, 15, 45-54.

Jago, J., Krohn, C., \& Matthews, L. (1999). The influence of feeding and handling on the development of the human-animal interactions in young cattle. Applied Animal Behaviour Science, 62(2-3), 137-151. http://doi.org/10.1016/S0168-1591(98)00219-6

Kaminski, J., Riedel, J., Call, J., \& Tomasello, M. (2005). Domestic goats, Capra hircus, follow gaze direction and use social cues in an object choice task. Animal Behaviour, 69(1), 11-18. http://doi.org/10.1016/j.anbehav.2004.05.008

Lakatos, G., Soproni, K., Dóka, A., \& Miklósi, Á. (2009). A comparative approach to dogs' (Canis familiaris) and human infants' comprehension of various forms of pointing gestures. Animal Cognition, 12(4), 621-631. http://doi.org/10.1007/s10071-009-0221-4

Maros, K., Gácsi, M., \& Miklósi, Á. (2008). Comprehension of human pointing gestures in horses (Equus caballus). Animal Cognition, 11(3), 457-466. http://doi.org/10.1007/s10071-008-0136-5

Miklósi, A., \& Soproni, K. (2006). A comparative analysis of animals' understanding of the human pointing gesture. Animal Cognition, 9(2), 81-93. http://doi.org/10.1007/s10071005-0008-1

Miura, A., Tanida, H., Tanaka, T., \& Yoshimoto, T. (1996). The influence of human posture and movement on the approach and escape behaviour of weanling pigs. Applied Animal Behaviour Science, 49, 247-256. http://doi.org/10.1016/0168-1591(95)00658-3

Muns, R., Rault, J.-L., \& Hemsworth, P. (2015). Positive human contact on the first day of life alters the piglet's behavioural response to humans and husbandry practices. Physiology \& Behavior, 151, 162-167. http://doi.org/10.1016/j.physbeh.2015.06.030

Nawroth, C., Ebersbach, M., \& von Borell, E. (2013). Are juvenile domestic pigs (Sus scrofa domestica) sensitive to the attentive states of humans? - The impact of impulsivity on 
choice behaviour. Behavioural Processes, 96, 53-58.

http://doi.org/10.1016/j.beproc.2013.03.002

Nawroth, C., Ebersbach, M., \& von Borell, E. (2014). Juvenile domestic pigs (Sus scrofa domestica) use human-given cues in an object choice task. Animal Cognition, 17(3), 701-713. http://doi.org/10.1007/s10071-013-0702-3

Probst, J. K., Spengler Neff, A., Leiber, F., Kreuzer, M., \& Hillmann, E. (2012). Gentle touching in early life reduces avoidance distance and slaughter stress in beef cattle. Applied Animal Behaviour Science, 139(1-2), 42-49. http://doi.org/10.1016/j.applanim.2012.03.002

Proops, L., Walton, M., \& McComb, K. (2010). The use of human-given cues by domestic horses, Equus caballus, during an object choice task. Animal Behaviour, 79(6), 12051209. http://doi.org/10.1016/j.anbehav.2010.02.015

Riedel, J., Schumann, K., Kaminski, J., Call, J., \& Tomasello, M. (2008). The early ontogeny of human - dog communication. Animal Behaviour, 75(3), 1003-1014. http://doi.org/10.1016/j.anbehav.2007.08.010

Soproni, K., Miklósi, Á., Topál, J., \& Csányi, V. (2002). Dogs’ (Canis familaris) responsiveness to human pointing gestures. Journal of Comparative Psychology, 116(1), 27-34. http://doi.org/10.1037//0735-7036.116.1.27

Stewart, M., Shepherd, H. M., Webster, J. R., Waas, J. R., McLeay, L. M., \& Schütz, K. E. (2013). Effect of previous handling experiences on responses of dairy calves to routine husbandry procedures. Animal, 7(5), 828-33. http://doi.org/10.1017/S175173111200225X

Tallet, C., Sy, K., Prunier, A., Nowak, R., Boissy, A., \& Boivin, X. (2014). Behavioural and physiological reactions of piglets to gentle tactile interactions vary according to their previous experience with humans. Livestock Science, 167, 331-341. http://doi.org/10.1016/j.livsci.2014.06.025

Udell, M. a. R., Dorey, N. R., \& Wynne, C. D. L. (2008). Wolves outperform dogs in following human social cues. Animal Behaviour, 76(6), 1767-1773. http://doi.org/10.1016/j.anbehav.2008.07.028

Waiblinger, S., Boivin, X., Pedersen, V., Tosi, M.-V., Janczak, A. M., Visser, E. K., \& Jones, R. B. (2006). Assessing the human-animal relationship in farmed species: A critical review. Applied Animal Behaviour Science, 101(3-4), 185-242. http://doi.org/10.1016/j.applanim.2006.02.001 